DOI 10.37882/2223-2982.2020.12-2.33

\title{
АНАЛИЗ ОСОБЕННОСТЕЙ КОММУНИКАЦИИ КАК КЛЮЧЕВОГО КОМПОНЕНТА ЭЛЕКТРОННОГО ОБУЧЕНИЯ ИНОСТРАННЫМ ЯЗЫКАМ БАКАЛАВРОВ В ВУЗАХ КИТАЯ И РОССИИ
}

\section{FOREIGN LANGUAGE TEACHING FOR CHINESE AND RUSSIAN STUDENTS AT UNIVERSITIES: A RESEARCH INTO FEATURES OF COMMUNICATION AS A KEY COMPONENT OF E-LEARNING}

\section{Sun Yanan \\ Liu Feng \\ Druzhinina Maria}

Summary: Massive educational organizations are changing to implement online learning, as a result of which the need for studying and applying e-learning is increased dramatically. However, it is found that researches on specifics of communication in the electronic educational environment are insufficient. Therefore, the researching problem of this article is to reveal specifics of foreign languages for bachelors in E-learning at universities in China and Russia. The goal of the study is to improve bachelor students' FLT (Foreign Language Teaching) efficiency in e-learning at universities in China and Russia. This research is based on theoretical and empirical methods with comparative aspects. It is found that specifics of communication between subjects in educational processes should be treated as a key component among varied specifics of E-learning for bachelors at universities in China and Russia. Similarities and differences in features of communication between subjects of the educational process in China and Russia are illustrated. With reference to the obtained results, a number of recommendations for foreign language teachers were correspondingly given. In addition, several modern teaching tools are we enlisted as a part of practical recommendations for FLT in E-learning.

Keywords: specifics of communication; E-learning; comparative research; China and Russia; FLT (Foreign Language Teaching).

\begin{abstract}
Сун Янань
аспирант, Северный (Арктический) федеральный университет имени М.В. Ломоносова, г. Архангельск

ya.sun@narfu.ru

Лю Фэн

соискатель, Северный (Арктический) федеральный университет имени М.В. Ломоносова, г. Архангельск real.fengliu@gmail.com

Дружинина Мария Вячеславовна

Д.п.н., дочент, Северный (Арктический) федеральный университет имени М.В. Ломоносова, г. Архангельск m.druzhinina@narfu.ru
\end{abstract}

Аннотация: В связи с массовым переходом образовательных организаций на онлайн-обучение потребность в изучении и применении электронного обучения резко возрастает. Однако, нами обнаружена недостаточность изучения специфики коммуникации в электронной образовательной среде. Таким образом, актуализировалась исследуемая проблема исследования специфики электронного обучения иностранным языкам бакалавров в вузах Китая и России с целью повышения эффективности электронного обучения ИЯ (Иностранным Языкам) бакалавров в вузах Китая и России. Исследование базируется на теоретических и эмпирических методах с сравнительно-сопоставительным аспектами. В работе утверждается, что специфику коммуникации между субъектами образовательного процесса следует рассматривать как ключевой компонент особенностей электронного обучения ИЯ бакалавров в вузах Китая и России. Нами также представлены сходства и отличия в особенностях коммуникации между субъектами образовательного процесса в Китае и России. В соответствии с полученным результатом составлен ряд рекомендаций для преподавателей ИЯ. Кроме того, изложен нами перечень современных средств как часть практических рекомендаций по электронному обучению ИЯ.

Ключевые слова: специфика коммуникации; электронное обучение; сравнительно-сопоставительный; Китай и Россия; обучение иностранным языкам.

\section{Введение}

$\ni$ лектронное обучение предоставляет инновационные и уникальные возможности для образования, В т.ч. профессионального. Онлайн-обучение, которое является одной из ключевых форм электронного обучения, стало широко использоваться в связи с массовым переходом образовательных организаций на дистанционные формы работы. Международные, государственные, общественные и личностные потребности в изучении, сравнении и выяснении специфики электронного обучения также быстро возрастают. Одной из существенных инноваций XXI в. является акцент на ком- паративистские, особенно на бинарные сопоставления процессов модернизации систем образования Китая и России [1]. Обучение иностранным языкам (ИЯ) выступает ключевым элементом в процессе модернизации и интернационализации систем всех стран, включая Китай и Россию. Таким образом, актуализировалась проблема исследования специфики электронного обучения иностранным языкам бакалавров в вузах Китая и России с целью повышения эффективности электронного обучения ИЯ бакалавров в вузах Китая и России.

В последнем десятилетии обращается большое внимание науправлениеучебным процессом (на английском 
языке этот термин звучит как classroom management). На фоне стремительного развития электронного обучения проблема управления широко обсуждается. П.Е. Уильямс (P.E. Williams), изучив задачи и роль преподавателей в электронном обучении в высших учебных заведениях, определил ряд их компетенций. По результатам его исследования компетенции преподавателей заключаются в четырех основных категориях: коммуникация и интеракция, использование ИКТ (Информационнокоммуникационные технологии), изучение и преподавание, менеджмент и администрация. П.Е. Уильямс также отмечает, что социальные и коммуникативные навыки играют ключевую роль и доминируют в первой десятке общих образовательных компетенций [2].

Ученые И. Альварез (I. Alvarez), Т. Гуаш (T. Guasch) и A. Эспаса (A. Espasa) также конкретизировали ряд компетенций, например, умение оценивать успеваемость студентов в электронном контексте; переводить традиционный контент в онлайн-контент с занятиями интерактивного характера для студентов; создавать онлайн интерактивное обучающее содержание и т.д. [3]. Кроме этих указанных компетенций, исследователи определили четыре ведущие функции роли преподавателей, включая планирование, проектирование, социальная функция и преподавание [там же]. По мнению этих исследователей особенно необходимо улучшение коммуникации между преподавателями и студентами, а также владение способами преодоления трудностей коммуникации как между преподавателями и студентами, так и самими студентами [там же]. Наряду с этим, И. Альварез и ее коллеги утверждают, что в образовательной практике преподавателям ИЯ часто необходимо уметь общаться и взаимодействовать с другими преподавателями и специалистами.

В процессе изучения научной литературы мы установили, что коммуникация в обучении, в т.ч. электронном обучении ИЯ бакалавров в вузах Китая и России, играет ключевую роль. Однако, нами также обнаружено, что внимание исследователей к данной проблеме недостаточно. Исследования, в которых обсуждаются цель, содержание, методы, средства, формы электронного обучения, затрагивают эту проблему довольно часто, но рассматривают ее не в полной мере. В некоторых случаях упоминается о проблеме, связанной с общением со студентами и преподавателями, но редко изучается специфика коммуникации в электронной образовательной среде. Например, в работе А.Г. Ковалевой [26] проведено сравнение между традиционным и электронным обучением, но не исследованы коммуникативные особенности обеих сред. В работе, связанной с интерактивным обучением, А.В. Обсков теоретически обсуждал общие проблемы при использовании коммуникативного подхода к обучению разным предметам, в т.ч. ИЯ [4]. Но, не было изложены исследователем особенности коммуникации в электронной образовательной среде и способы решения проблемы коммуникации [4; 5].

Следует особо подчеркнуть, что сущность понятия «технология», особенно образовательных технологий, заключается в коммуникации [6]. Также необходимо указать, что коммуникативные компетенции у обучающихся в университетском языковом образовании выступают одними из ключевых [7; 8; 9; 10]. Наряду с этим, отметим, что коммуникативный подход является одним из ведущих подходов к обучению ИЯ в современном университетском образовании $[10 ; 11 ; 12 ; 13]$.

Исходя из изложенного, мы констатируем, что в процесс решения проблемы изучения специфики электронного обучения ИЯ бакалавров в Китае и России следует включать изучение проблемы коммуникации между субъектами образовательного процесса в качестве ключевого компонента.

Особенность мотивации студентов к изучению ИЯ [14; 15], срок, сложность и объем самостоятельной работы студентов [16; 17], уровень автономии студентов [18; 19], состояние инфраструктуры ИКТ [20, с. 28], уровень цифровой грамотности и готовности преподавателей и студентов к электронному обучению [там же, с. 132-135], развитие образовательной мобильности [21], содержание языковой политики в вузе или стране [22], «согласование целей, содержания, организации и оснащения курса обучения между ответственными за конкретный курс обучения, деканами, представителями комиссий по образованию и координации» $[23$, с. 56] и др. могут быть другими компонентами в исследовании специфики электронного обучения ИЯ бакалавров в Китае и России. Однако, следует признать, что в рамках одной статьи, анализ всех компонентов не представляется возможным. Таким образом, в данной работе мы рассматриваем особенности коммуникации между субъектами образовательного процесса как ключевого компонента электронного обучения ИЯ бакалавров в вузах Китая и России.

\section{Методология (материалы и метод исследования)}

В работе известного ученого Б.Л. Вульфсона указано, что информация из различных первоисточников (в нашем случае это анкетирование) дополняет понимание, полученное на основе изучения научных трудов [24, с. 126]. Вопросы, отобранные и проанализированные согласно данным анкеты из исследования, изложенного в диссертации одного из соавторов данной статьи', составлены на английском и русском языках. Эти вопросы фокусируется на методах преодоления трудностей коммуникации (14 вопросов) и изучении отношения субъек-

1 Liu F. Classroom management and motivation in EFL classes in China and Russia. Master dissertation. Arkhangelsk. - 2016. - 78 p. 
тов к коммуникативному обучению (6 вопросов). Следует отметить, что в анкете была использована 5-балльная шкала Лайкерта, а именно: от 1 (неважно) до 5 (очень важно).

Вопросы о методах коммуникации представлены как следующие:

1. Demonstrate friendly and respectful attitude to students (демонстрирование дружелюбного и уважительного отношения к студентам).

2. Have informal talks with students during break (неформальное общение со студентами на перерывe).

3. Show enthusiasm for the subject (демонстрирование интереса к предмету).

4. Empathize students' capability of answering (учет способности студентов).

5. Propose English names for students (использование английских имен).

6. Make no language mistakes (обучение без языковых ошибок).

7. Establish a set of goals and academic expectations and make them clear to students at the beginning of a term (постановка целей и выяснение академических ожиданий в начале семестра).

8. Plan and improvise questions well (сдача тщательно подготовленных и импровизированных вопроCOB).

9. Use the Socratic method (questioning and discussions) (проведение сократических диалогов).

10. Promptly and relevantly share associated life experience in Chinese (Russian) with students (спонтанно делиться со студентами актуальным жизненным опытом на китайском / русском языке).

11. Promptly and relevantly share associated life experience in English with students (спонтанно и адекватно делиться со студентами актуальным жизненным опытом на английском языке).

12. Create tasks that are challenging and interesting (создание интересных и полезных задач).

13. Inject information from diverse sources (e.g. textbooks, research articles, multimedia, Internet) (использование разнообразной образовательной информации).

14. Organize cultural activities, like Halloween, Thanksgiving day (организация внеклассных мероприятий).

Вопросы об отношении к коммуникативному обучению представлены в следующей форме:

1. Enhance the process of discussion between students during class (значимость общения между студентами).

2. Stimulate students to express their own opinions (стимулирование студентов к выражению собственного мнения).
3. Create communicative or interactive activities intended for cooperative learning (pair and group work, projects, etc.) (создание коммуникативных или интерактивных действий, предназначенных для совместного обучения в парах, группах и проектной работе).

4. Teach language issues (grammar and vocabulary) in separate lessons with much focus on formal features and drilling exercises (обучение грамматике и лексике путем тренировочных упражнений).

5. Ensure active participation of all students during the lesson (обеспечение активного участия всех студентов на занятии).

6. Lecture at length on particular topics with the demand for students' attention (длинная лекция по конкретным темам с привлечением внимания студентов).

Анкетирование было создано и проведено на английском языке в двух вузах: Китайском Университете Иностранных Дел (China Foreign Affairs University, CFAU) в Пекине (Китай) и Северном (Арктическом) Федеральном университете имени М.В. Ломоносова (САФУ) в Архангельске (Россия). Студенты обучались на первом курсе по специальности «лингвистка». Опрос проводился в четырех группах из обоих университетов. Все преподаватели обучения английскому языку заполняли анкеты. Культурные особенности образовательных учреждений Китая и России учитывались при опросе и позволили получить: 84 ответа студентов из Китая (4 группы) и 10 ответов от их преподавателей в CFAU; 32 ответа студента из России (4 группы) и 3 ответа от преподавателей САФУ.

В разработке данных был использован метод -Квартили (Three quartiles, Q1, Q2 и Q3). Цель применения данного метода состоит в определении существования отличия между ответами на каждый вопрос респондентами из Китая и России. Первый квартиль (Q1) определяется как среднее число между наименьшим числом и медианой набора данных. Второй квартиль (Q2) - это медиана данных. Третий квартиль (Q3) - это среднее значение между медианой и наибольшим значением в наборе данных. В нашем исследовании определено, что если разница в баллах по каждому пункту между респондентами меньше, чем Q1 или больше, чем Q3, то разница по этому пункту является значительной. Число наших статистических данных является четным.

Цель применения U-критерия Манна-Уитни согласно полученным статистическим данным, заключается в том, чтобы определить значительно ли отличие мнений респондентов о двух фокусированных аспектах. Таким образом, мы сравнивали расчет значения U с критическим значением U (U0). Также определим нулевую гипотезу (Р0) следующим образом: исследуемые аспекты не воспринимаются в отношении друг друга по-разному с точки зрения статистического распределения. Альтер- 
нативная гипотеза является противоположной. Для расчета уровень значимости определяется как 0,05, а гипотеза является двусторонней.

\section{Результаты исследования}

В соответствии с полученными статистическими данными, обнаружены три наиболее благоприятных метода преодоления трудностей коммуникации среди преподавателей из Китая в порядке возрастания - это учет способности студентов, постановка целей и академических ожиданий в начале семестра и демонстрирование дружелюбного и уважительного отношения к студентам; три наименее благоприятных метода преодоления трудностей коммуникации среди преподавателей из Китая в порядке возрастания - это использование английских имен, организация внеклассных мероприятий, а также спонтанное деление актуальным жизненным опытом со студентами на английском языке. Далее, отметим, что среди преподавателей из России три наиболее благоприятных метода преодоления трудностей коммуникации в порядке возрастания - это демонстрирование энтузиазма по предмету, постановка целей и академических ожиданий в начале семестра, создание интересных и полезных задач, а три наименее благоприятных метода преодоления трудностей коммуникации в порядке возрастания - это неформальное общение со студентами на перерыве, использование английских имен, проведение сократических (философских) диалогов. В связи с этими результатами заметна значительная разница в предпочтениях между преподавателями обеих стран.

Методы «Квартили» и «U-критерий Манна-Уитни» позволяют глубже наблюдать отличия и сходства тех или иных явлений. В следующих рисунках отражены результаты проведенного сравнения.

На рисунке 1 (см. Рисунок 1) показаны отличия в мнениях о методах преодоления трудностей коммуникации всех преподавателей. Согласно полученным результатам, выяснилось, что преподаватели из Китая дали более высокие баллы следующим методам: неформальное общение со студентами на перерыве (2-ой пункт), учет способностей студентов (4-ый пункт) и использование сократических диалогов (10-ый пункт). Преподаватели из России оценили выше следующие методы: обучение без языковых ошибок (6-ой пункт), организация внеклассных мероприятий (14-ый пункт). Таким образом, мы считаем, что, несмотря на разницу в порядке предпочтенных методов, в целом мнения преподавателей Китая и России отличаются незначительно, что соответствует результату анализа U-критерия Манна-Уитни. На основе результатов, отображенных на рисунке 2 (см. Рисунок 2), сделан вывод, что все преподаватели позитивно относятся к коммуникативному обучению. Согласно полученным ответам по первому вопросу (значимость общения между студентами), преподаватели из Китая дали более высокие баллы, чем преподаватели из России. И, наоборот, значимость грамматических упражнений (4-ый пункт) была оценена преподавателями из России выше, чем преподавателями из Китая. На основе анализа U-критерия Манна-Уитни мнение преподавателей из обеих стран в данном аспекте отличается незначительHо.

Для того, чтобы выяснить особенности коммуникации субъектов в Китае и России, мы проанализировали мнения преподавателей и студентов, учитывая, что мнение студентов в современном образовании оценивается очень высоко [25]. Более того, следует отметить, что метод эффективен в одной культуре и возможно недостаточно эффективен в другой культуре. В связи с этим, результаты по сравнению методов преодоления трудностей коммуникации отражены на следующих рисунках (см. Рисунок 3, Рисунок 4).

На основе анализа полученных данных, мы пришли к таким выводам:

1. между респондентами из Китая больше отличий, чем между респондентами из России. Это показывает, что студенты из России в большей степени ценят преподавательские методы преодоления трудностей коммуникации, чем студенты из Китая;

2. по анализу пятого показателя у студентов из обеих стран имеется одинаковое мнение об использовании английских имен. Однако, преподаватели из обеих стран дали более низкую оценку этому методу, чем студенты;

3. на основе анализа, отображенного на рисунке 3, студенты из Китая ожидают больше таких интересных моментов на уроках, как рассказы личного опыта преподавателя на китайском языке (10-ый показатель) и внеклассные мероприятия (14-ый показатель). Преподаватели из Китая отмечают эти моменты меньше;

4. на рисунке 4 показано, что студенты из России в большей степени ожидают сократические диалоги (10-ый показатель), чем их преподаватели. Если провести сравнение ответов студентов из России на десятый вопрос с ответами студентов из Китая, то студенты из России предпочитают общение с преподавателями на английском языке. Это показывает высокую внутреннюю мотивацию у студентов из России к изучению ИЯ;

5. преподаватели из Китая ожидают улучшение коммуникации в основном путем учета способностей студентов (4-ый показатель), сдачи тщательно подготовленных и импровизированных вопросов (8-ой показатель), а также путем использования сократических диалогов (10-ый показатель). Студенты из Китая проявили менее выраженное желание улучшать коммуникацию описанными выше путями;

6. преподаватели из России считают, что постановка 


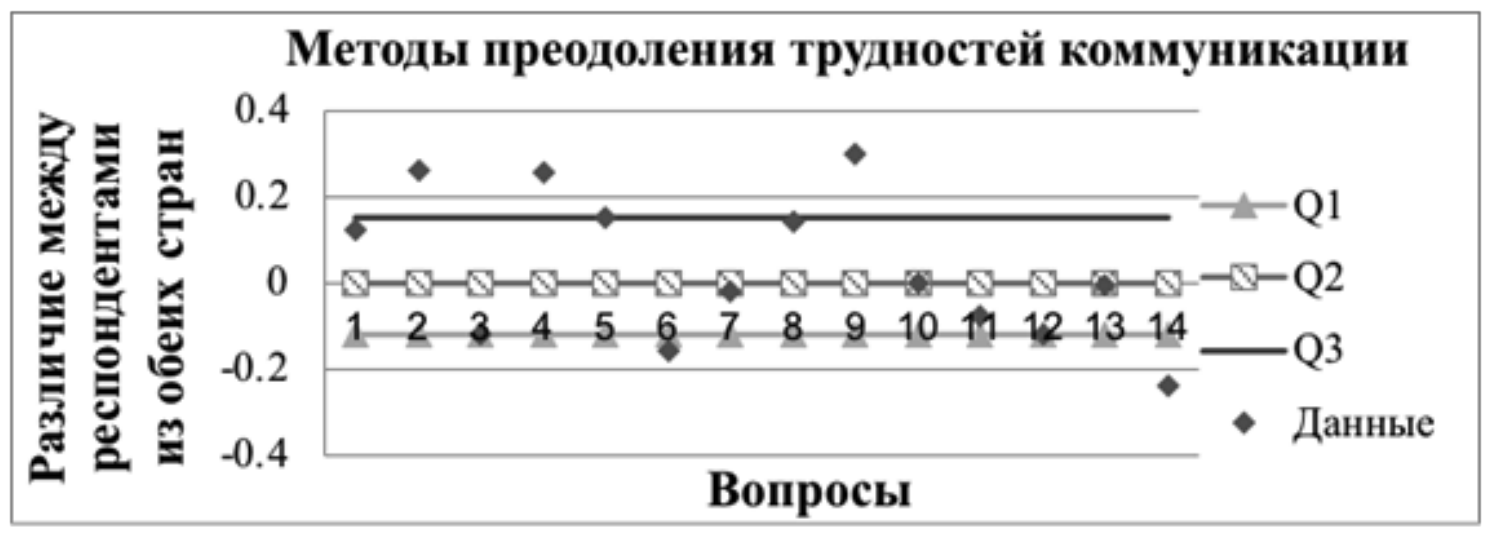

Рис. 1. Сравнение мнений преподавателей из обеих стран

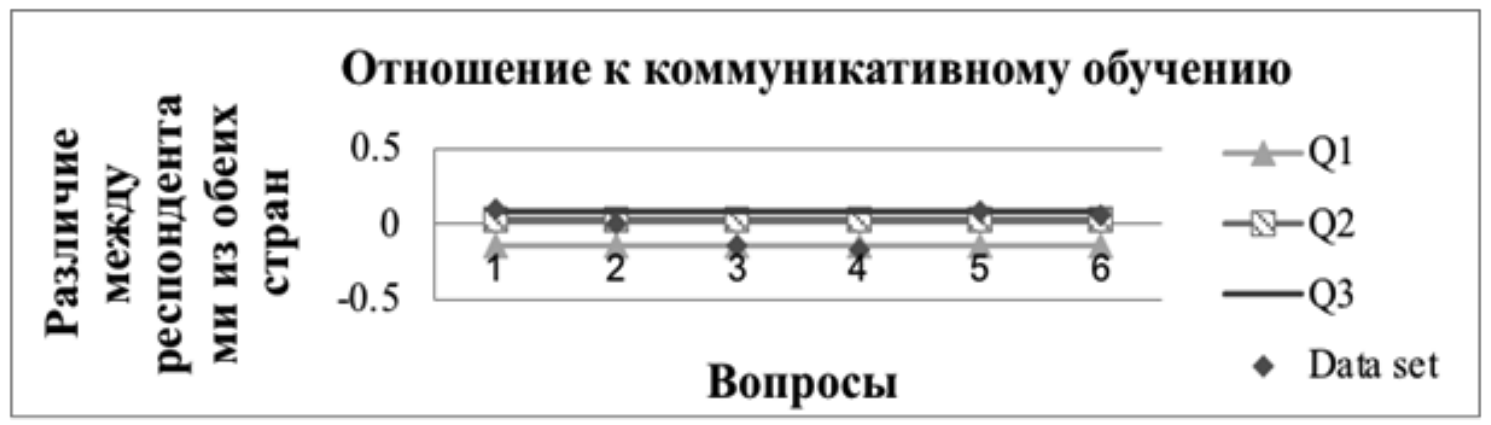

Рис. 2. Сравнение мнений преподавателей из обеих стран

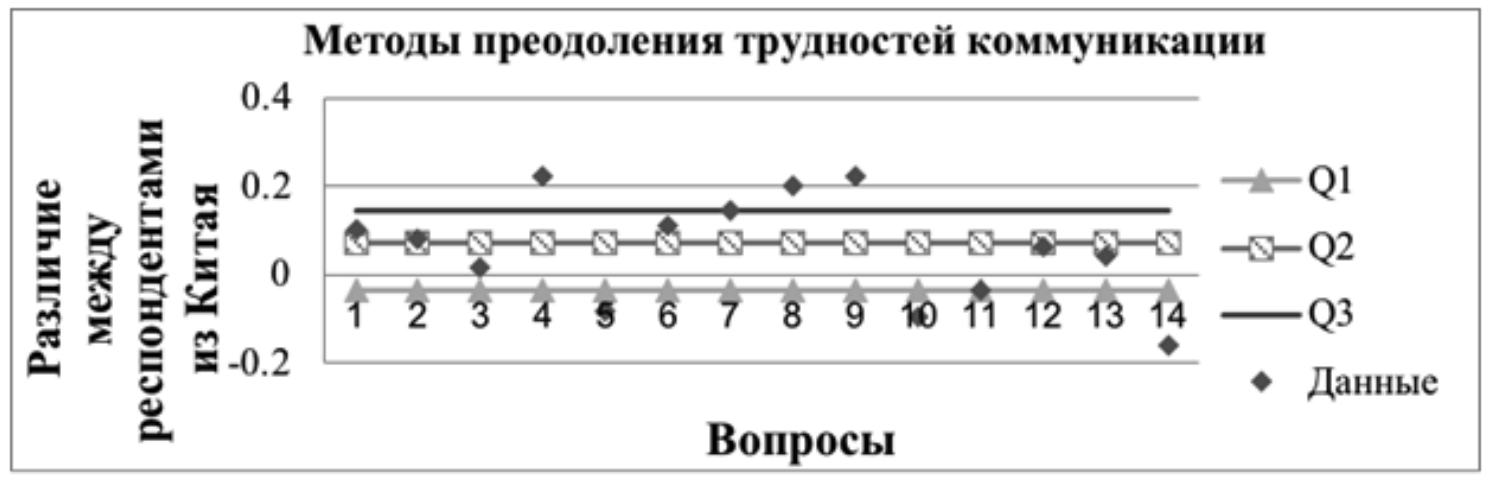

Рис. 3. Сравнение мнений преподавателей и студентов из Китая

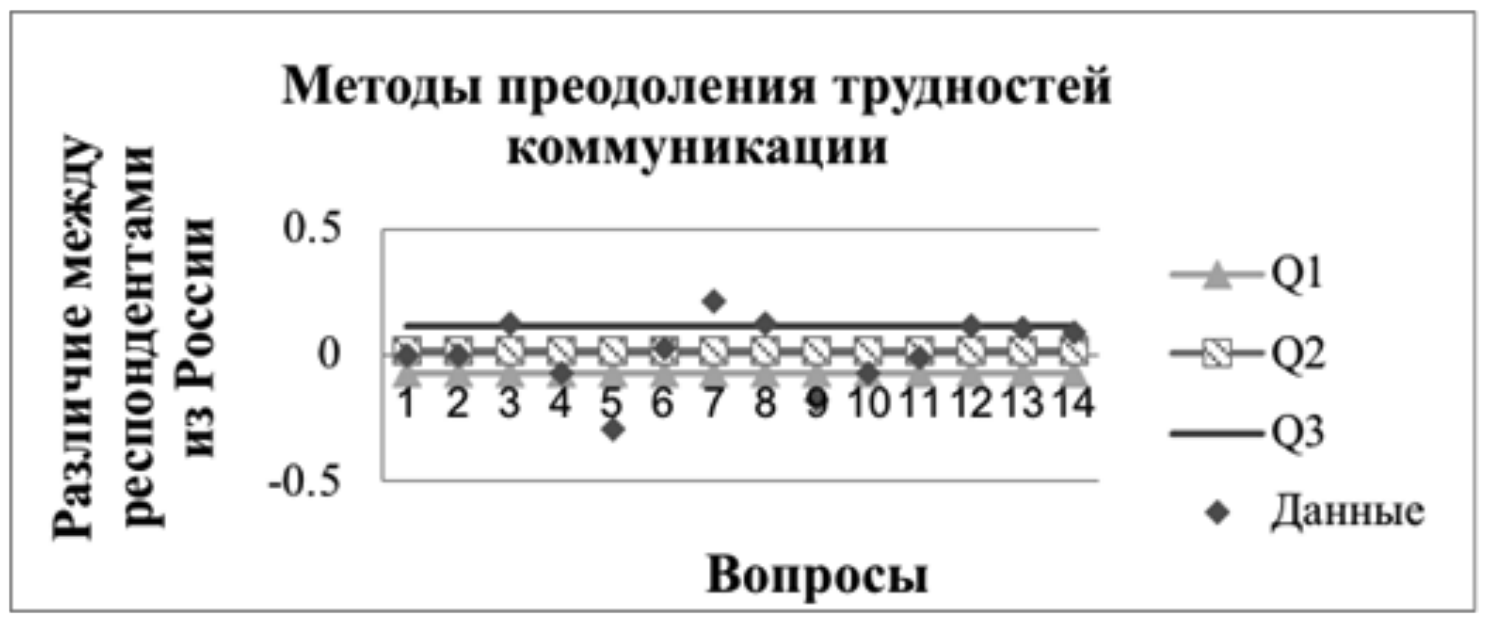

Рис. 4. Сравнение мнений преподавателей и студентов из России 


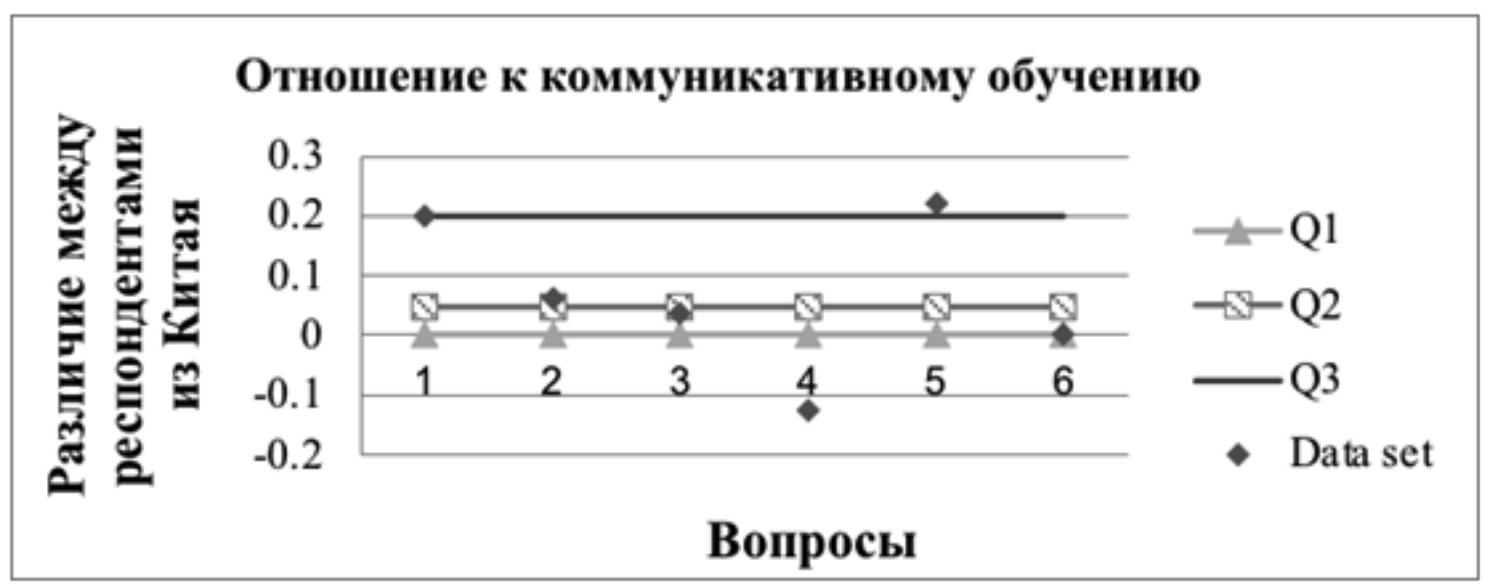

Рис. 5. Сравнение мнений преподавателей и студентов из Китая

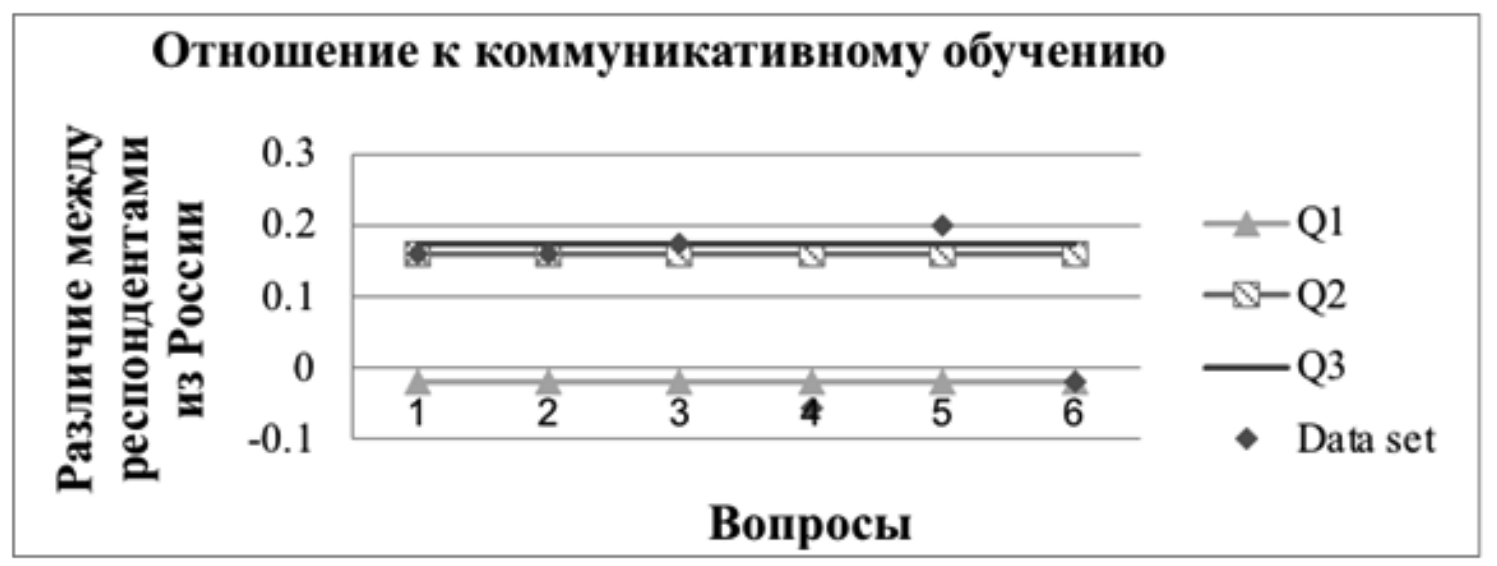

Рис. 6. Сравнение мнений преподавателей и студентов из России

целей и академических ожиданий в начале семестра более важна для успеха дальнейшей коммуникации (8-ой показатель), это не в полной мере совпадает с мнением студентов из России;

7. по результату метода U-критерия Манна-Уитни установлено, что в целом мнение респондентов из обеих групп отличается незначительно.

На рисунках (см. Рисунок 5, Рисунок 6) представлены различия в отношении респондентов из обеих стран к коммуникативному обучению.

На основе анализа полученных данных установлено, что:

1. в целом в ответах респондентов из обеих стран имеется большое сходство. Также согласно методу U-критерием Манна-Уитни, между ответами от студентов и преподавателей обеих стран не зафиксирована значительная разница;

2. отношение респондентов обеих стран к четвертому и пятому вопросам о значимости грамматических упражнений (4-ый показатель) и активного участия студентов в дискуссиях (5-ый показатель) имеет общие черты. Нами выявлено, что обучающиеся желают использовать коммуникативный подход к обучению сильнее, чем их преподаватели. В ответах преподавателей на пятый вопрос зафиксировано сильное желание активного участия всех студентов в коммуникации;

3. отношение всех респондентов к коммуникативному обучению является положительным.

Таким образом, резюмируя изложенное, отметим, что:

1. специфика коммуникации между субъектами образовательного процесса представлена в двух аспектах особенностей коммуникации, включая методы преодоления трудностей коммуникации и отношение к коммуникативному обучению путем изучения трех ракурсов сравнения, а именно путем сравнения мнений преподавателей из обеих стран, преподавателей и студентов из Китая, преподавателей и студентов из России;

2. отношение всех респондентов, особенно студентов к коммуникативному обучению положительно. То есть, коммуникативное обучение играет ведущую роль в обеих странах;

3. у всех преподавателей выявлены отличительные предпочтения в выборах методов преодоления трудностей коммуникации на уроках ИЯ. Однако, 
Таблица 1

Современные средства обучения иностранному языку (ИЯ) (Foreign Language Teaching)

\begin{tabular}{|c|c|c|c|}
\hline Наименование средств & Основная функция & Бесплатно / платно & Система \\
\hline $\begin{array}{l}\text { Словарь современного английского } \\
\text { языка Лонгмана }\end{array}$ & $\begin{array}{l}\text { Словарь с возможностью оценить произношение каждого } \\
\text { слова из словарей баллами }\end{array}$ & частично бесплатно & IOS, Андроид \\
\hline Люлишуо & $\begin{array}{l}\text { Программа организации игровой деятельности с целью из- } \\
\text { учения английского языка }\end{array}$ & бесплатно & IOS, Андроид, ПК \\
\hline Пигай & $\begin{array}{l}\text { Программа автоматической оценки сочинений студентов на } \\
\text { ИЯ в баллах с указанием рекомендаций обучающимся }\end{array}$ & бесплатно & IOS, Андроид, ПК \\
\hline Байсицжань, Мемрайз, Дуолингво & $\begin{array}{l}\text { Инструмент, персонализированный для изучения слов с ис- } \\
\text { пользованием геймификации }\end{array}$ & бесплатно & IOS, Андроид, ПК \\
\hline Клэвербот, Эвибот & Общение с ботом на разных языках & бесплатно & IOS, Андроид, ПК \\
\hline МООК платформы & $\begin{array}{l}\text { Открытые онлайн обучающие курсы по разным учебным } \\
\text { дисциплинам на разных языках, большинство из которых на } \\
\text { английском языке. }\end{array}$ & частично бесплатно & IOS, Андроид, ПК \\
\hline Хеллоток, Тандем & Общение с людьми, интересующихся изучением ИЯ & бесплатно & IOS, Андроид, ПК \\
\hline Дуолингво, Каучсерфинг & $\begin{array}{l}\text { Офлайн местное мероприятие и личная встреча с носителем } \\
\text { языка }\end{array}$ & частично бесплатно & IOS, Андроид, ПК \\
\hline $\begin{array}{l}\text { Итоки, Дуолингво, Чайнизпод, МООК } \\
\text { платформы, Ютуб и т.д. }\end{array}$ & Открытые форумы для изучения ИЯ & бесплатно & IOS, Андроид, ПК \\
\hline Кахоот & $\begin{array}{l}\text { Инструмент для создания интерактивных учебных опросов, } \\
\text { викторин и тестов }\end{array}$ & бесплатно & IOS, Андроид, ПК \\
\hline Камбли & 0бщение с носителем языка по гибкому режиму & платно & IOS, Андроид, ПК \\
\hline Go Correct - Big Languages & $\begin{array}{l}\text { Общение и корректировка от квалификационного учителя } \\
\text { английского языка }\end{array}$ & частично бесплатно & IOS, Андроид, ПК \\
\hline Skribbl & Интерактивная и игровая форма обучения ИЯ & бесплатно & IOS, Андроид, ПК \\
\hline
\end{tabular}

в соответствии с результатом анализа U-критерия Манна-Уитни, установлено, что мнение преподавателей из Китая и России в целом отличается незначительно;

4. в целом особенности коммуникации субъектов образовательного процесса между Китаем и Россией демонстрируют больше общих черт, чем отличных.

\section{Зак^ючение}

В данной статье обосновано, что в специфику электронного обучения ИЯ бакалавров в Китае и России включается проблема коммуникации между субъектами образовательного процесса в качестве ключевого компонента. Рекомендации преподавателям обеих стран в основном базируются на мнении студентов и на отличном мнении российских и китайских коллег. Согласно полученным результатам сравнительно-сопоставительного анализа специфики коммуникации между субъектами образовательного процесса, мы пришли к выводу, что электронное обучения ИЯ бакалавров в вузах Китая будет эффективнее, если преподаватели будут предлагать коммуникативные методы обучения, нетрадиционные формы работы над грамматикой и лексикой, организовывать внеаудиторные мероприятия, неформально общаться со студентами и др. Для электронного обучения ИЯ бакалавров в вузах России мы рекомендуем уменьшить количество упражнений по грамматике, чаще использовать коммуникативные типы заданий, например, выразить свое мнение или отношение к новому тренду и давать оценку эссе и других творческих работ друг друга, а также интегрировать в обучение когнитивные задания, например, в стиле сократических обсуждений различных проблем.

Отметим, что активное применение современных средств в электронном обучении в вузах Китая и России является неотъемлемой частью технологий электронного обучения, В т.ч. технологий электронного обучения ИЯ. С этой целью представим ряд современных средств как часть практических рекомендаций по электронному обучению ИЯ (см. Таблица 1).

Также подчеркнем, что современные обучающие средства непрерывно обновляются, поэтому в процессе их внедрения следует обратить внимание на технологии электронного обучения ИЯ, которые дают возможность решения проблем в языковом образовании в современных условиях. 


\section{ЛИТЕРАТУРА}

1. Борисенков В.П. Сотрудничество ученых России и Китая продолжается // Педагогика. - 2019. № 83(12). - C. 109-116. URL: http://www.pedagogika-rao.ru/ journals/2019/12/

2. Williams P.E. Roles and competences for distance education programs in higher institutions // The American Journal of Distance Education. -2000 . № $17(1)$. - P. 45-57. URL: https://www.learntechlib.org/p/97196/

3. Alvarez I. University teacher roles and competencies in online learning environments: a theoretical analysis of teaching and learning practices // European Journal of Teacher Education. - 2009. № 32(3). - P. 321-336. D0I: 10.1080/02619760802624104

4. Обсков А.В. К проблеме организации интерактивного обучения иностранному языку в вузе // Вестник Томского государственного педагогического университета. - 2012. № 11(126). - C. 120-124. URL: https://cyberleninka.ru/article/n/k-probleme-organizatsii-interaktivnogo-obucheniya-inostrannomuyazyku-v-vuze

5. Обсков А.В., Глухий Я.А. Использование интерактивного обучения иностранному языку в высших учебных заведениях // Современные проблемы науки и образования. - 2014. № 3. - C. 1-8. URL: https://www.science-education.ru/ru/article/view?id=13555

6. Liu F., Zashikhina I.M., Druzhinina M.V., Sun Y. On the Essence of Technology (the Case of Collaboration between Chinese and Russian Enterprises) // Proceeding of IOP Conference Series: Materials Science and Engineering. - 2019. № 483(1). - P. 1-7. D0I: 10.1088/1757-899X/483/1/012095

7. Антонянян М.А. Устранение пробелов в знаниях как условие повышения качества иноязычной подготовки студентов неязыкового вуза // Педагогика. 2019. № 9. - C. 87-95. URL: http://www.pedagogika-rao.ru/journals/2019/09/

8. Lee C.P. Shaping the vision for service-learning in language education // Foreign Language Annals. - 2018. № 51(1). - P. 169-184. D0I: 10.1111/flan.12329

9. Meiramova S., Akylbaeva A., Shaibakova D. Profession-oriented language learning in multilingual education perspectives // Proceeding of the 7th International Conference on Education and New Learning Technologies (EDULEARN). - Spain: Barcelona, 2015. - C. 2382-2388. URL:https://www.researchgate.net/ publication/287196133_professionoriented_language_learning_in_multilin-gual_education_perspectives

10. Niyazova A.Y., Mussagozhina K., Kabdenova A.B., Lukpanova A.E., Kozhakanova M.T., Meiramova S. Modeling learning situations of verbal communication in professionally oriented teaching English for students in the sphere of transport logistics // XLinguae. - 2018. № 11(2). - P. 190-205. D0I: 10.18355/ XL.2018.11.02.15

11. Дружинина М.В. Формирование языковой образовательной политики университета как фактора обеспечения качества профессиональной подготовки современных специалистов: монография. - Архангельск: Поморский университет, 2007. - 471 с.

12. Li F., Ge L., Wang J., Liu F. Applied Participatory Learning for teaching Nuclear Majored Students Professional English in China // Integration of Education. - 2019. № 23(2). - P. 182-195. DOI: 10.15507/1991-9468.095.023.201902

13. Harmer J. The Practice of English Language Teaching. Pearson Education ESL / Handbook. - London: Person Education Limited, 2001. - 370 p. URL: https://www. academia.edu/23486893/the_practce_of_English_language_Jeremy_Harmer

14. Гедиева Е.Б., Боташева 3.Х. Мотивация студента: психолого-правовой анализ // Педагогика. - 2019. № 83(11). - C. 103-107. URL: http://www.pedagogikarao.ru/journals/2019/11/

15. Liu F., Druzhinina M.V. Motivation for English as a Foreign Language learning in China and Russia // World of Science. Pedagogy and psychology. - 2018. № 6(6). P. 1-8. URL: https://mir-nauki.com/PDF/34PDMN618.pdf

16. Юсупова Г.А. Формирование социально-психологической компетентности студентов на занятиях по изучению китайского языка // III Российско-Китайской конференции «Двухстороннее научно-образовательное сотрудничество вузов России и Китая»: материалы. - Москва, 2009. - C. 57-68. URL: https:// www.elibrary.ru/item.asp?id=21740925

17. Сарсекеева Ж.Е., Жекибаева Б.А., Жукенова Г.Б., Сарсекеева Н.Е., Маженова Р.Б. Взаимосвязи между уровнями сформированности умений самостоятельной работы студентов и их успеваемостью по педагогике // Science for Education Today. - 2019. № 9(6). - C. 7-18. D0I: 10.15293/26586762.1906.01

18. Насонова Е.А. Автономное обучение: парадигма языкового образования // Высшее образование в России. - 2007. № 2. - C. 113-115. URL: https:// cyberleninka.ru/article/n/avtonomnoe-obuchenie-paradigma-yazykovogo-obrazovaniya

19. Хонамри Ф., Азизи М., Кралик Р., Использование интерактивного электронного перевернутого обучения для улучшения критического чтения студентов // Science for Education Today. - 2020. № 10(1). - C. 25-42. URL: http://sciforedu.ru/article/4327

20. Бадарч Д. Информационные и коммуникационные технологии в образовании: монография. - М.: ИИТО ЮHЕCKO, 2013. - 320 c. URL: https://obuchalka. org/2017121798035/informacionnie-i-kommunikacionnie-tehnologii-v-obrazovanii-monografiya-badarch-dendev-2013.html

21. Snegurenko A.P. Using E-Learning Tools to Enhance Students Mathematicians' Competences in the Context of International Academic Mobility Programmes // Integration of Education. - 2019. № 23(1). - P. 8-22. D0I: 10.15507/1991-9468.094.023.201901.008-022

22. Дружинина М.В. Языковое образование: отношение университетского и внеуниверситетского сообщества // Высшее образование в России. - 2007. № 5. - C. 60-64. URL: https://cyberleninka.ru/article/n/yazykovoe-obrazovanie-spetsialista-otnoshenie-universitetskogo-i-vneuniversitetskogo-soobschestva

23. Агафонова Л.И., Дружинина М.В., Евшова И.В., Комарова Ю.А., Невзорова А.В., Соколова М.Л., Суслонова С.А. Современное языковое образование в системе «бакалавриат - магистратура -аспирантура». Монография. - Архангельск: Поморский университете, 2009. - 227 c. URL: https://rucont.ru/ efd/175353 
24. Wolhuter C, Popov N., Leutwyler B., Ermenc K.S. Comparative Education at Universities World Wide. Third Expanded edition. Handbook. - Sofia: Investpress, 2013. - 416 p. URL: https://www.researchgate.net/profile/Bruno_Leutwyler/publication/302273706_Comparative_Education_at_Universities_World_Wide_Third_ Expanded_Edition/links/572f3eca08ae74415190465b/Comparative-Education-at-Universities-World-Wide-Third-Expanded-Edition.pdf

25. LiY. Quality Assurance in Chinese Higher Education // Research in Comparative \& International Education. - 2010. № 5(1). - P. 58-76. D0I: 10.2304/ rcie.2010.5.1.58

26. Ковалева А.Г. Обучение иностранному языку студентов радиотехнических направлений подготовки на основе мультимедийных трансформаций. Екатеринбург. - 2016. - 220 c. URL: https://www.dissercat.com/content/obuchenie-inostrannomu-yazyku-studentov-radiotekhnicheskikh-napravlenii-podgotovkina-osnove

( Сун Янань (ya.sun@narfu.ru), Лю Фэн (real.fengliu@gmail.com), Дружинина Мария Вячеславовна (m.druzhinina@narfu.ru).

Журнал «Современная наука: актуальные проблемы теории и практики»

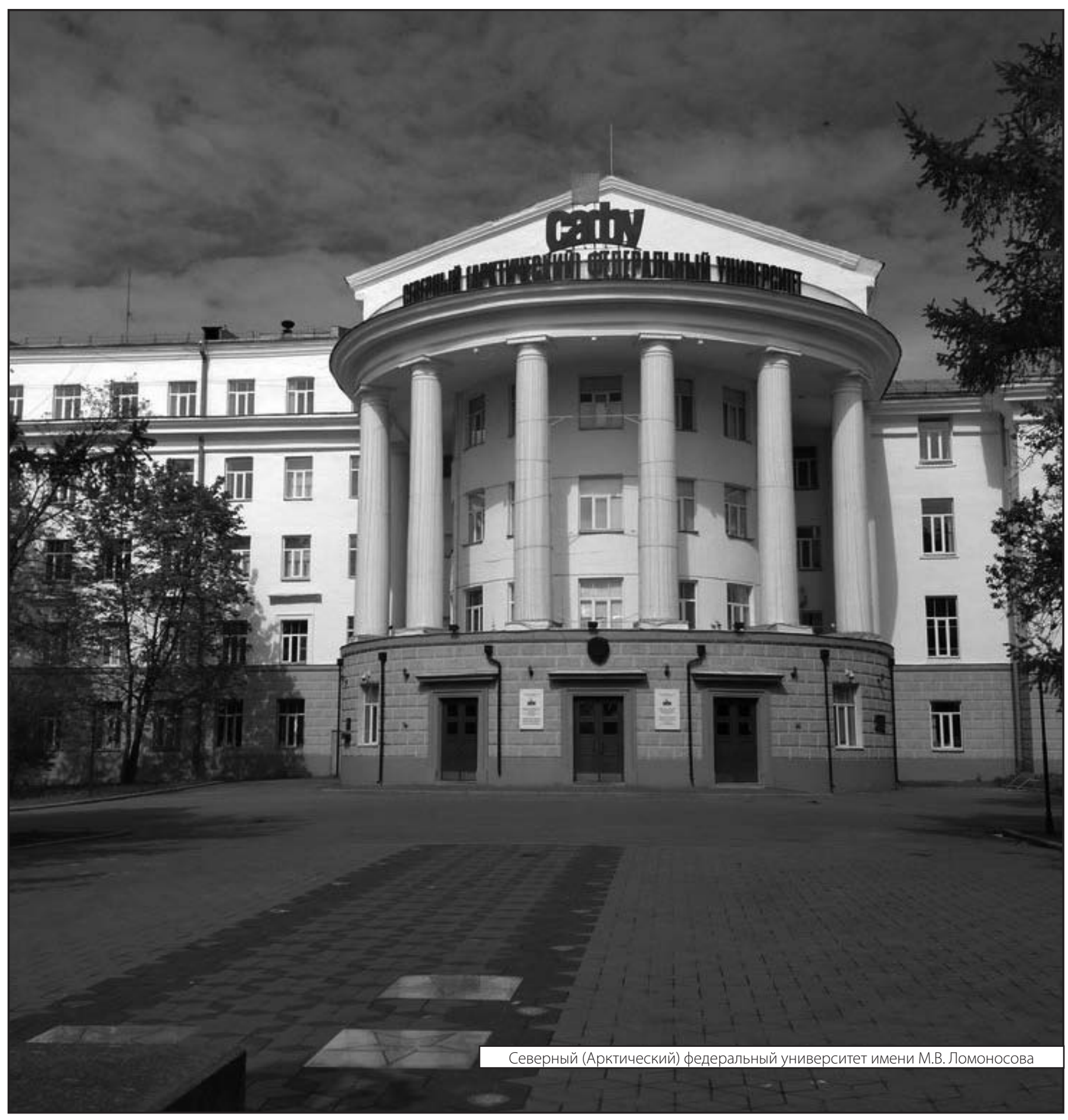

